\title{
Sensitivity of a long-period optical fiber grating bend sensor
}

\author{
Rathje, Jacob; Svalgaard, Mikael; Hübner, Jörg; Kristensen, Martin
}

Published in:

Technical Digest Optical Fiber Communication Conference and Exhibit

Link to article, DOI:

10.1109/OFC.1998.657360

Publication date:

1998

Document Version

Publisher's PDF, also known as Version of record

Link back to DTU Orbit

Citation (APA):

Rathje, J., Svalgaard, M., Hübner, J., \& Kristensen, M. (1998). Sensitivity of a long-period optical fiber grating bend sensor. In Technical Digest Optical Fiber Communication Conference and Exhibit (pp. 238-239). IEEE. https://doi.org/10.1109/OFC.1998.657360

\section{General rights}

Copyright and moral rights for the publications made accessible in the public portal are retained by the authors and/or other copyright owners and it is a condition of accessing publications that users recognise and abide by the legal requirements associated with these rights.

- Users may download and print one copy of any publication from the public portal for the purpose of private study or research.

- You may not further distribute the material or use it for any profit-making activity or commercial gain

- You may freely distribute the URL identifying the publication in the public portal 
length. We improved the gain of about $0.7 \mathrm{~dB}$ and the NF of $0.9 \mathrm{~dB}$ as changing the splice loss optimizing wavelength from $980-1550 \mathrm{~nm}$.

In saturation region of EDFAs, the splice loss must be optimized at pump wavelength, because small signal loss can not affect the gain and output power of amplifiers but the loss of pump power is very important in saturation region. As shown in Fig. 3, we demonstrated that saturated output power was maximum when the splice loss was minimized at wavelength of $980 \mathrm{~nm}$, on the other hand the NF was minimum as the splice loss was minimized at $1550 \mathrm{~nm}$ still.

In summary, we have measured and analyzed the performances of EDFAs as changing the spectral splicing conditions. From the results of experiment, we could know the followings.

The gain and NF of amplifiers were improved by changing the minimum loss wavelength from $980 \mathrm{~nm}$ (pump wavelength) to $1550 \mathrm{~nm}$ (signal wavelength) such as $0.8 \mathrm{~dB}$ and $0.9 \mathrm{~dB}$ respectively. As changing the minimum loss wavelength from $1550-980 \mathrm{~nm}$, the saturated output power of amplifiers increased about $0.3 \mathrm{~dB}$ but NF was degraded about $0.9 \mathrm{~dB}$.

${ }^{\star}$ Daewoo Telecom

1. M. Kihara et al., IEICE Trans. Commun. E76-B, (January 1993).

2. W. Zheng et al., IEEE J. Lightwave Technol. 12, (1994).

3. M. Kihara et al., IEEE J. Lightwave Technol. 14, (1996).

4. H.K. Seo et al., presented at OECC'97, July 1997, paper 9EP-14.

\section{WM49}

\section{Sensitivity of a long-period optical fiber grating bend sensor}

J. Rathje, M. Svalgaard, J. Hübner, M. Kristensen, Mikroelektronik Centret, Bldg. 345 east, Technical University of Denmark, DK-2800 Lyngby, Denmark

Long-period optical fiber gratings have found various applications including sensors for temperature, strain, and refractive index ${ }^{1,2}$ and for

a)
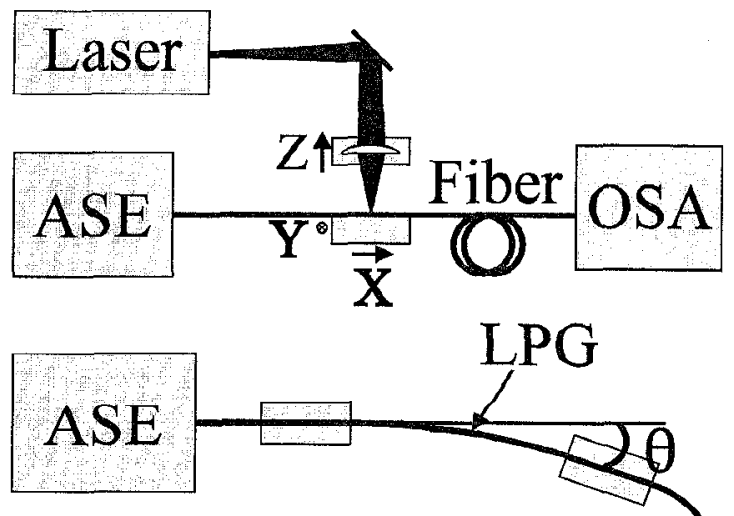

b)

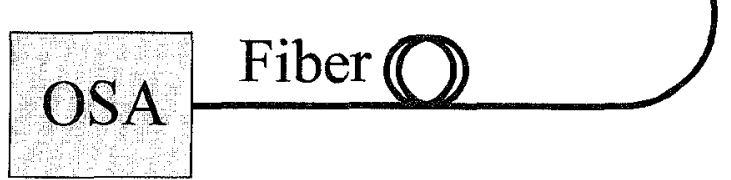

WM49 Fig. 1. (a) Setup for writing long-period gratings in fibers. Using an amplified spontaneous emission (ASE) source and an optical spectrum analyser (OSA) the formation of the grating can be monitored. (b) Characterization of the bend sensitivity.

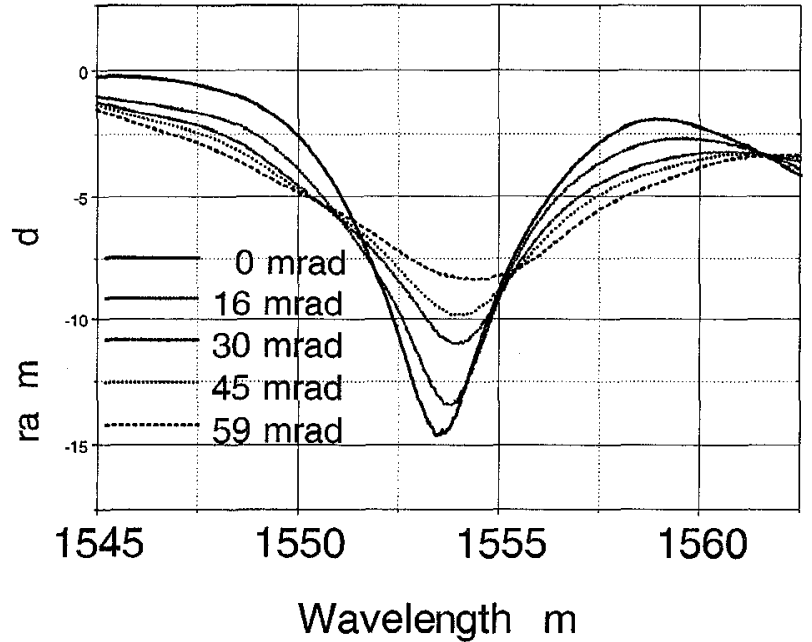

WM49 Fig. 2. Transmission spectra obtained with varying degrees of bend applied to the long-period grating.

gain flattening of erbium-doped fiber amplifiers. ${ }^{3}$ In addition, a large sensitivity of the transmission spectrum to bends of the host fiber has been reported. ${ }^{1}$ In order to take advantage of this large sensitivity we have systematically examined the bend sensitivity obtainable by a long-period grating.

Long-period fiber gratings are written using a frequency doubled $\mathrm{cw}$ argon ion laser producing $30 \mathrm{~mW}$ at $244 \mathrm{~nm}$, as shown in Fig. 1(a). By scanning the fiber under the beam and varying the scan speed between $100 \mathrm{~m} / \mathrm{s}$ and $1 \mathrm{~cm} / \mathrm{s}$ in a stepwise fashion a periodic variation of the refractive index is created with a period 7 .

To characterize the bend sensitivity the fiber is mounted in two fiber holders $7 \mathrm{~cm}$ apart, as shown in Fig. 1(b). The angle, 2, between the holders can be varied from $0-70 \mathrm{mrad}$ and for each angle the positions of the holders are adjusted so that the fiber follows a circular arc.

A long-period grating with $7=400: \mathrm{m}, 50 \%$ duty cycle and a total length of $2 \mathrm{~cm}$ was written in a $\mathrm{D}_{2}$-loaded $3.5 \mathrm{~mol} \% \mathrm{GeO}_{2}$-doped single-mode fiber. The transmission spectrum for different bend angles is shown in Fig. 2. For increasing bend angles the resonance dip becomes shallower while the bandwidth increases. The shift in the center wavelength indicates tension in the fiber.

Figure 3 shows the transmission at resonance as a function of the fiber bend angle. $A$ linear curve fit shows that the grating has a bend coefficient of $0.77 \mathrm{~dB} \mathrm{~cm} / \mathrm{mrad}$ (the $\mathrm{cm}$ is from normalisation with the

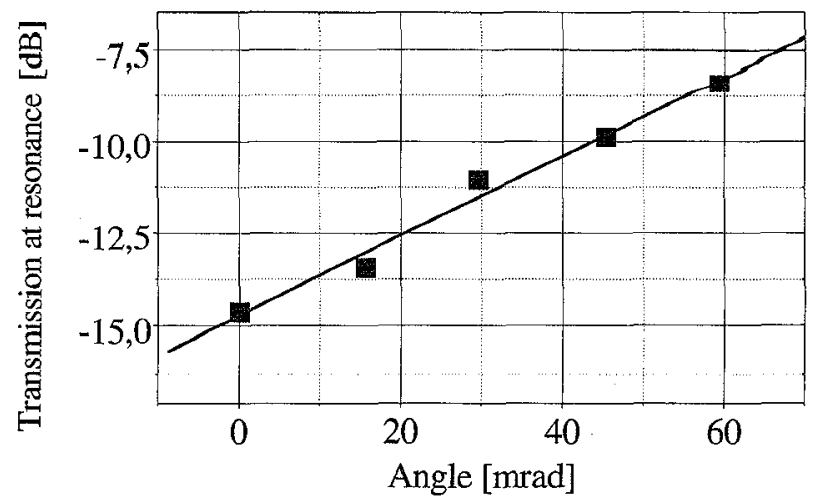

WM49 Fig. 3. Transmission at resonance as function of fiber bend angle. A linear dependence is observed. 
bend length). With an average uncertainty in the resonance minima on the OSA transmission spectrum of $0.04 \mathrm{~dB}$ this gives a sensitivity on approximately $0.05 \mathrm{mrad} / \mathrm{cm}$. This corresponds to an approximately $200 \mathrm{~m}$ radius of curvature.

In conclusion we have investigated the sensitivity of long-period fiber gratings and found a bend coefficient of $0.77 \mathrm{~dB} \mathrm{~cm} / \mathrm{mrad}$. In the current setup this corresponds to the ability of detecting curvatures with a radius up to approximately $200 \mathrm{~m}$.

1. V. Bhatia, T. D'Alberto, K.A. Murphy, R.O. Claus, Proc. SPIE 2718, 110, (1996).

2. V. Bhatia and A.M. Vengsarkar, Opt. Lett. 21, 692 (1996).

3. A.M. Vengsarkar, P.J. Lemaire, J.B. Judkins, V. Bhatia, T. Erdogan, J. Sipe, IEEE J. Lightwave Technol. 14, 58 (1996).

\section{WM50}

\section{Broadband polarization-insensitive all-fiber acousto- optic modulator}

Y.W. Koh, S.H. Yun,* Y.K. Kim, H.S. Seo,** S.R. Han,** K. Oh,** U.C. Paek,** B.Y. Kim,* FiberPro, TIC, 373-1 Kusong-dong, Yusong-gu, Taejon, 305-701, Korea; E-mail: ywkoh@fiberpro.kaist.ac.kr

Two-mode fiber devices based on mode coupling between the fundamental and second-order modes have been demonstrated as frequency shifters and tunable wavelength filters. ${ }^{1}$ The spectral bandwidth of the devices is determined by the dispersion of the beat length between the two coupled modes. It has been known ${ }^{2}$ that the beat length has a minimum where the two spatial modes have the same group velocity, making it possible to realize broadband devices. This occurs at $V \approx 3$ in the case of step-index, circular-core fibers, where $V=(2 \pi / \lambda) r_{c o}\left(r_{c o}{ }^{2}-\right.$ $\left.\mathrm{n}_{\mathrm{ct}}{ }^{2}\right)^{1 / 2}$ is the normalized frequency. In this work, we demonstrate a broadband, low loss, and polarization-independent acousto-optic ( $\mathrm{AO}$ ) modulator by using a two-mode fiber that was designed to have $\mathrm{V} \approx 3$ around $1550 \mathrm{~nm}$. The device can be useful in wavelength-division multiplexing (WDM) communication systems where, for example, signal power variations at erbium-doped fiber amplifiers (EDFAs), associated with channel add/drop, need to be controlled to avoid output power transients. ${ }^{3}$ With the addition of a mode-selective coupler, ${ }^{4}$ the device can also be operated as a $1 \times 2$ switch. $^{5}$

Figure 1 shows a schematic of the switch based on AO mode coupling via the flexural acoustic wave. ${ }^{1}$ When the acoustic wavelength matches the beat length, resonant coupling takes place. A two-mode fiber $\left(\mathrm{n}_{\mathrm{\varepsilon o}}-\mathrm{n}_{\mathrm{cl}} \approx 0.007\right.$, core radius of $\mathrm{r}_{\mathrm{co}} \approx 5 \mu \mathrm{m}$, clad diameter of $\left.80 \mu \mathrm{m}\right)$ was spliced to conventional single-mode fibers with a minimal core misalignment to minimize the unwanted excitation of the second-mode fibers with a minimal core misalignment to minimize the unwanted excitation of the second-order mode. Mode strippers employing a tight bending of the two-mode fiber ensure only the fundamental mode to

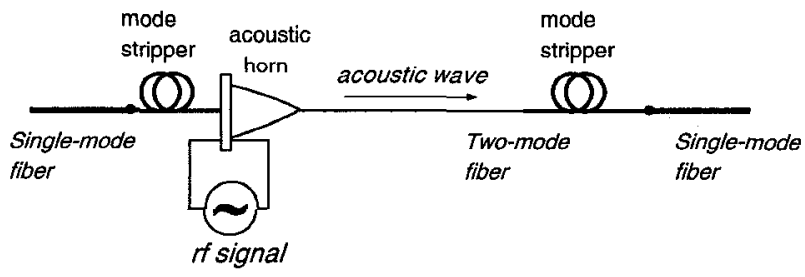

WM50 Fig. 1. Schematic of two-mode-fiber AO modulator. enter and exit the $25-\mathrm{mm}$-long $\mathrm{AO}$ interaction region where the polymer jacket of the fiber was stripped off.

Figure 2(a) shows the phase-matching acoustic frequency, which is approximately inversely proportional to the square of beatlength as a function of the optical wavelength. It is clear that the beat length has a minimum around $1550 \mathrm{~nm}$. When the acoustic frequency was 2.024 $\mathrm{MHz}$, mode coupling was observed over $80 \mathrm{~nm}$ from $\lambda=1510 \mathrm{~nm}$ to $1590 \mathrm{~nm}$ with only a fraction of a dB variation in rejection efficiency, as shown in Fig. 2(b). The rejection efficiency was controllable up to $18 \mathrm{~dB}$ with negligible polarization dependence in the $80-\mathrm{nm}$ range. The excess loss of the device was $\angle 1 \mathrm{~dB}$ due to the splices and mode strippers.

Figure 3 shows switching characteristics of the device measured by using an external cavity laser diode and an amplitude modulated if source. The switching time was $\sim 10 \mu$ s, which should be fast enough to compensate the add/drop power transients in an EDFA. ${ }^{3}$ The initial delay of $\sim 7 \mu$ s was due to the acoustic wave propagation time in the acoustic horn shown in Fig. 1. The switching characteristics were almost the same for the three test wavelengths of 1525,1545 , and $1560 \mathrm{~nm}$.

In summary, we have demonstrated a broadband, polarizationinsensitive, low-loss $\mathrm{AO}$ modulator by using a two-mode fiber designed to provide a flat-top broadband spectral response. The device has a simple all-fiber construction, and can be a potentially low-cost AO

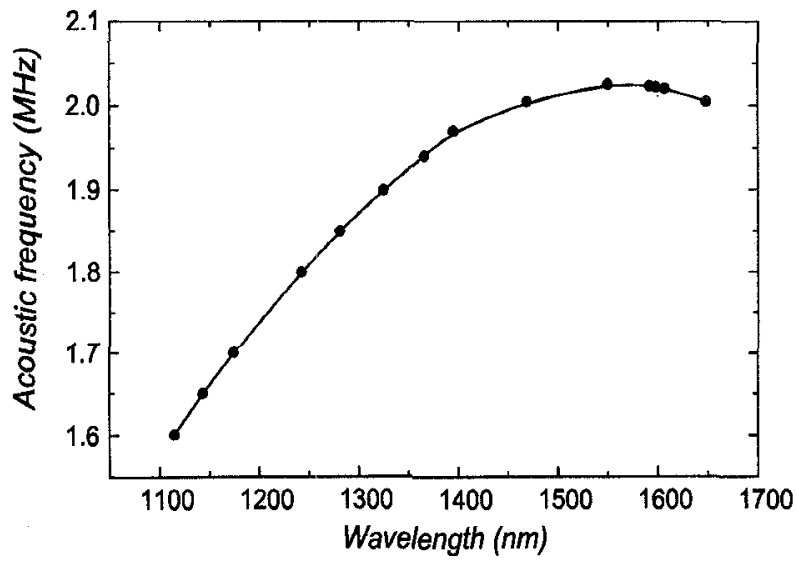

(a)

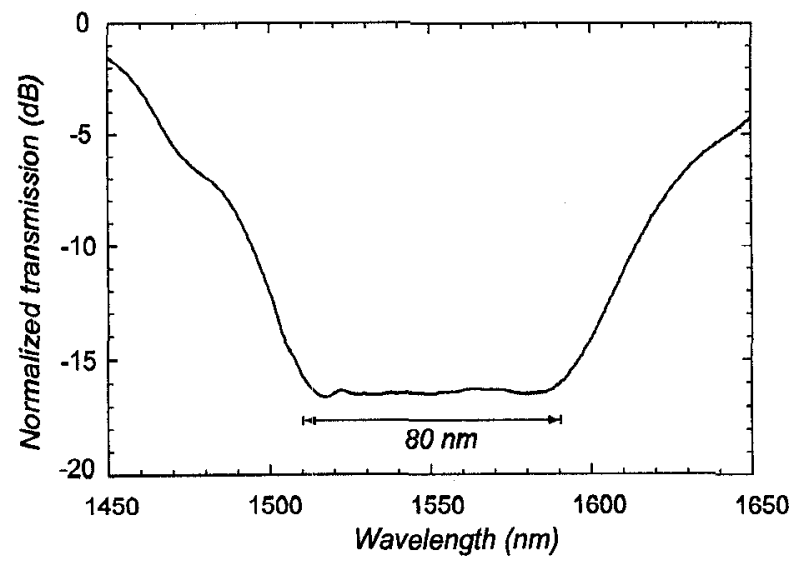

(b)

WM50 Fig. 2. (a) Phase-matching acoustic frequency as a function of optical wavelength. Broadband coupling occurs around $1550 \mathrm{~nm}$. (b) Transmission spectrum of the AO modulator measured using a unpolarized source when the rejection efficiency was adjusted to $16 \mathrm{~dB}$ in a $80 \mathrm{~nm}$ range around $1550 \mathrm{~nm}$. 